\title{
Let us rethink research for $A C L$ injuries: a call for a more complex scientific approach
}

\author{
Alli Gokeler ${ }^{1}$ Evert Verhagen ${ }^{2,3,4,5} \cdot$ Michael T. Hirschmann ${ }^{6,7}$
}

Received: 8 January 2018 / Accepted: 28 February 2018 / Published online: 5 March 2018

(c) European Society of Sports Traumatology, Knee Surgery, Arthroscopy (ESSKA) 2018



Alli Gokeler

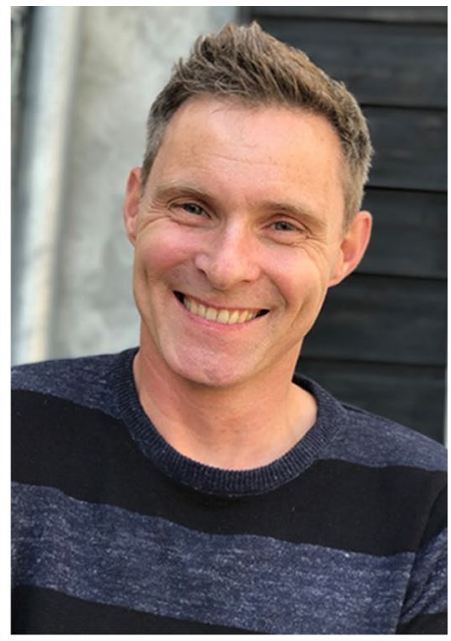

Evert Verhagen



Michael T . Hirschmann
The complex anatomy and function of the knee have been well recognized [5]. Understanding and explaining a complex biological system such as the knee joint are often difficult and challenging. To overcome the problem of complexity, many scientists simplify or reduce this complexity

Michael T. Hirschmann

michael.hirschmann@ksbl.ch;

michael.hirschmann@unibas.ch

http://www.kneedoctor.ch

Alli Gokeler

a.gokeler@rug.nl

Evert Verhagen

e.verhagen@vumc.nl

1 University of Groningen, University Medical Center Groningen, Center for Human Movement Sciences, UMCG sector F, FA 23, PO Box 196, 9700 AD Groningen, The Netherlands

2 Amsterdam Collaboration for Health and Safety in Sports (ACHSS), IOC Research Center, Academic Medical Center/VU Medical Center, Amsterdam, The Netherlands by disassembling the complex system into their single units. However, the knee joint is not a simple machine put together by bones, muscles, and connective tissue. Importantly, clinicians do not treat knees, but a person who has a knee problem.

3 Department of Public and Occupational Health, Amsterdam Movement Sciences, VU University Medical Center, Amsterdam, The Netherlands

4 Australian Centre for Research into Injury in Sport and its Prevention (ACRISP), Federation University Australia, Ballarat, VIC, Australia

5 Division of Exercise Science and Sports Medicine, Department of Human Biology, University of Cape Town, Cape Town, South Africa

6 Department of Orthopaedic Surgery and Traumatology, Kantonsspital Baselland (Bruderholz, Liestal, Laufen), 4101 Bruderholz, Switzerland

7 University of Basel, Faculty of Medicine, Basel, Switzerland 
Reductionism has been the basis of most scientific fields, and has led to an impressive range of discoveries and advancements.

How can we apply this to enhance our understanding of prevention and treatment of various knee pathologies? To understand how the knee joint works, one could dissect the knee and place all soft tissue and bony parts on a counter top. Looking now at the patella and the popliteal artery, does this gives us an idea how the knee joint functions as a whole? It appears that a reductionistic approach is also widely used in ACL research, in particular when aiming for identification of isolated risk factors for ACL injuries [1]. Given that ACL injuries are multifactorial in nature, limitations of univariate analysis of ACL injury have been reported [6].

In contrast to reductionism, a complex systems theory is a field of science studying how parts of a system give rise to the collective behaviors of the system, and how the system interacts with its environment in the broadest sense [4]. A complex system approach that highlights a non-linear interaction between risk factors from different scales (biomechanical, psychological and physiological characteristics) [2]. Risk factors and their interactions are often unknown and the direct relationship with the injury is weak or even non-existent. Only in case of an inciting an injury may occur [2]. In other words, ACL prevention research should focus on the analysis of the observable regularities arising from the existing and complex interactions among the elements of the web of determinants and not the units (risk factors) themselves [2].

In case of an ACL reconstruction, one could argue that a part in the human machine has been replaced (ACL graft), and subsequently, the machine should function normally again. Another view could be, in analogy to a car, that patients after ACL reconstruction have rebuilt transmissions and these are not the same as the factory transmissions (native ACL) [3]. In contrast to cars, humans form a biological system with an inherent capability to adapt to changes. This is also where the complexity lies, as large inter-individual differences may arise as to how humans respond to these changes.

Some patients may indeed return to normal function and achieve their full potential and participate (sports, work) at the same level as before the injury. Others, however, have to reduce their activity.

A patient should be viewed as a complex system with non-linear relationships between units (i.e., biomechanical, behavioural, physiological, and psychological factors) that give rise to the collective behaviour of the athlete [2].

\section{References}

1. Bahr R (2016) Why screening tests to predict injury do not workand probably never will: a critical review. Br J Sports Med. https ://doi.org/10.1136/bjsports-2016-096256

2. Bittencourt NF, Meeuwisse WH, Mendonca LD, Nettel-Aguirre A, Ocarino JM, Fonseca ST (2016) Complex systems approach for sports injuries: moving from risk factor identification to injury pattern recognition-narrative review and new concept. Br J Sports. https://doi.org/10.1136/bjsports-2015-095850

3. Dye S (1996) The knee as a biologic transmission with an envelope of function. Clin Orthop Relat Res 325:10-18

4. Galea S, Riddle M, Kaplan GA (2010) Causal thinking and complex system approaches in epidemiology. Int J Epidemiol 39:97-106

5. Hirschmann MT, Muller W (2015) Complex function of the knee joint: the current understanding of the knee. Knee Surg Sports Traumatol Arthrosc 23:2780-2788

6. Vacek PM, Slauterbeck JR, Tourville TW, Sturnick DR, Holterman LA, Smith HC, Schultz SJ, Johnson RJ, Tourville KJ, Beynnon BD (2016) Multivariate analysis of the risk factors for firsttime noncontact ACL injury in high school and college athletes: a prospective cohort study with a nested, matched case-control analysis. Am J Sports Med 44:1492-1501 